Supplement of Earth Surf. Dynam., 5, 479-492, 2017

https://doi.org/10.5194/esurf-5-479-2017-supplement

(C) Author(s) 2017. This work is distributed under

the Creative Commons Attribution 3.0 License.

(c) (1)
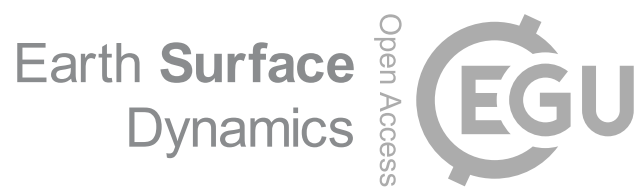

Supplement of

\title{
Quantifying the controls on potential soil production rates: a case study of the San Gabriel Mountains, California
}

\section{Jon D. Pelletier}

Correspondence to: Jon D. Pelletier (jdpellet@email.arizona.edu)

The copyright of individual parts of the supplement might differ from the CC BY 3.0 License. 
Table S1. Data used in the paper. Sample ID, location, elevation (z), mean slope $\left(S_{\text {av }}\right), P$ values, and soil thickness $(h)$ are from Heimsath et al. (2012).

\begin{tabular}{|c|c|c|c|c|c|c|c|c|c|c|c|}
\hline Sample ID & $\begin{array}{c}\text { Latitude } \\
\left({ }^{\circ}\right)\end{array}$ & $\begin{array}{c}\text { Longitude } \\
\left({ }^{\circ}\right)\end{array}$ & $z(\mathrm{~m})$ & $\begin{array}{l}S_{\mathrm{av}} \\
\left({ }^{\circ}\right)\end{array}$ & $\begin{array}{c}P \\
\text { (m/Myr) }\end{array}$ & $\begin{array}{c}P \\
\text { error } \\
(\mathrm{m} / \mathrm{Myr}) \\
\end{array}$ & $\begin{array}{c}h \\
(\mathrm{~cm})\end{array}$ & $\begin{array}{c}P_{\mathrm{r}} \\
(\mathrm{m} / \mathrm{Myr})\end{array}$ & $\begin{array}{c}P_{\mathrm{r}} \\
\text { error }\end{array}$ & $\begin{array}{c}D \\
(\mathrm{~m} / \mathrm{m})\end{array}$ & $\begin{array}{r}P_{\mathrm{r}, \mathrm{pred}} \\
(\mathrm{m} / \mathrm{Myr}\end{array}$ \\
\hline SG-1 & 34.2090 & -117.7714 & 1072 & 30 & 300 & 38 & 0 & 300 & 38 & 24.8 & 174 \\
\hline SG-2 & 34.2118 & -117.7685 & 1072 & 30 & 240 & 19 & 0 & 240 & 19 & 25.6 & 174 \\
\hline SG-6 & 34.1868 & -117.7632 & 947 & 35 & 460 & 148 & 0 & 818 & 263 & 24.5 & 522 \\
\hline SG-7 & 34.1856 & -117.7662 & 950 & 35 & 373 & 34 & 5 & 427 & 39 & 23.1 & 522 \\
\hline SG-10 & 34.207 & -117.7621 & 855 & 18 & 68 & 5 & 38 & 221 & 16 & 26.4 & 154 \\
\hline SG-101 & 34.2852 & -118.1519 & 1673 & 35 & 156 & 32 & 0 & 278 & 57 & 19.0 & 522 \\
\hline SG-102 & 34.2852 & -118.1519 & 1673 & 35 & 251 & 51 & 30 & 564 & 115 & 19.0 & 522 \\
\hline SG-103 & 34.3717 & -118.0710 & 2015 & 26 & 78 & 17 & 23 & 159 & 35 & 8.3 & 169 \\
\hline SG-104 & 34.3717 & -118.0710 & 2015 & 26 & 21 & 9 & 30 & 53 & 23 & 8.3 & 169 \\
\hline SG-105 & 34.3707 & -118.0701 & 2005 & 26 & 48 & 12 & 43 & 182 & 46 & 8.0 & 169 \\
\hline SG-106 & 34.3706 & -118.0692 & 1990 & 26 & 51 & 13 & 36 & 156 & 40 & 9.2 & 169 \\
\hline SG-107 & 34.3569 & -118.0631 & 1804 & 26 & 164 & 29 & 15 & 261 & 46 & 9.2 & 169 \\
\hline SG-108 & 34.3543 & -118.0580 & 1625 & 26 & 113 & 23 & 15 & 180 & 37 & 9.1 & 169 \\
\hline SG-110 & 34.2931 & -118.0199 & 1725 & 26 & 106 & 20 & 10 & 145 & 27 & 18.9 & 169 \\
\hline SG-111 & 34.2930 & -118.0202 & 1721 & 26 & 63 & 15 & 44 & 246 & 59 & 19.1 & 169 \\
\hline SG-112 & 34.2932 & -118.0211 & 1729 & 26 & 44 & 9 & 27 & 102 & 21 & 18.7 & 169 \\
\hline SG-113 & 34.2908 & -118.0218 & 1650 & 26 & 44 & 10 & 34 & 126 & 29 & 19.6 & 169 \\
\hline SG-115 & 34.2832 & -118.0263 & 1390 & 15 & 138 & 33 & 10 & 188 & 45 & 20.5 & 145 \\
\hline SG-153 & 34.3273 & -117.7998 & 2194 & 29 & 90 & 18 & 20 & 167 & 33 & 24.7 & 173 \\
\hline SG-154 & 34.3460 & -118.0060 & 1800 & 12 & 43 & 10 & 44 & 168 & 39 & 16.1 & 133 \\
\hline SG-155 & 34.3469 & -118.0059 & 1790 & 12 & 50 & 13 & 54 & 267 & 69 & 16.1 & 133 \\
\hline SG-156 & 34.3476 & -118.0061 & 1780 & 12 & 12 & 3 & 45 & 48 & 12 & 16.1 & 133 \\
\hline SG-200 & 34.3586 & -117.9922 & 1710 & 13 & 68 & 13 & 16 & 112 & 21 & 15.8 & 137 \\
\hline SG-201 & 34.3589 & -117.9920 & 1710 & 13 & 69 & 13 & 10 & 94 & 18 & 15.7 & 137 \\
\hline SG-202 & 34.3590 & -117.9922 & 1706 & 13 & 72 & 13 & 15 & 115 & 21 & 15.7 & 137 \\
\hline SG-203 & 34.3592 & -117.9923 & 1702 & 13 & 109 & 20 & 10 & 149 & 27 & 15.6 & 137 \\
\hline SG-07-009 & 34.3215 & -118.0866 & 1132 & 15 & 69 & 12 & 28 & 164 & 29 & 8.6 & 145 \\
\hline SG-07-011 & 34.3320 & -117.9483 & 2137 & 20 & 93 & 18 & 12 & 135 & 26 & 26.9 & 159 \\
\hline SG-07-012 & 34.3318 & -117.9481 & 2128 & 20 & 84 & 17 & 20 & 156 & 32 & 27.1 & 159 \\
\hline SG-07-013 & 34.3318 & -117.9481 & 2120 & 24 & 121 & 24 & 20 & 225 & 45 & 27.1 & 166 \\
\hline SG-07-014 & 34.3318 & -117.9481 & 2115 & 24 & 156 & 32 & 24 & 328 & 67 & 27.1 & 166 \\
\hline SG-07-015 & 34.3259 & -117.9517 & 1897 & 24 & 139 & 26 & 0 & 139 & 26 & 26.5 & 166 \\
\hline SG-07-016 & 34.3276 & -117.9507 & 1965 & 24 & 130 & 25 & 0 & 130 & 25 & 29.6 & 166 \\
\hline SG-07-017 & 34.3304 & -117.9498 & 2068 & 24 & 147 & 28 & 0 & 147 & 28 & 27.8 & 166 \\
\hline SG-07-019 & 34.3484 & -118.0045 & 1773 & 12 & 10 & 2 & 49 & 46 & 9 & 18.2 & 133 \\
\hline SG-07-020 & 34.3482 & -118.0035 & 1785 & 12 & 46 & 12 & 50 & 217 & 57 & 19.6 & 133 \\
\hline SG-07-021 & 34.3471 & -118.0030 & 1802 & 12 & 71 & 16 & 35 & 210 & 47 & 18.3 & 133 \\
\hline SG-07-023 & 34.3627 & -117.9108 & 1958 & 31 & 427 & 145 & 25 & 839 & 285 & 27.5 & 308 \\
\hline SG-07-024 & 34.3615 & -117.9107 & 1912 & 31 & 315 & 61 & 5 & 360 & 70 & 27.2 & 308 \\
\hline SG-07-025 & 34.3614 & -117.9110 & 1889 & 31 & 266 & 54 & 7 & 321 & 65 & 27.1 & 308 \\
\hline SG-07-031 & 34.3348 & -117.9695 & 1973 & 21 & 210 & 41 & 13 & 314 & 61 & 23.6 & 161 \\
\hline SG-07-032 & 34.3348 & -117.9695 & 1973 & 21 & 210 & 38 & 3 & 230 & 42 & 23.6 & 161 \\
\hline SG-07-033 & 34.3348 & -117.9695 & 1973 & 21 & 92 & 18 & 20 & 171 & 33 & 23.6 & 161 \\
\hline SG-07-034 & 34.3348 & -117.9695 & 1973 & 21 & 132 & 25 & 5 & 154 & 29 & 23.6 & 161 \\
\hline SG-07-035 & 34.3264 & -117.9690 & 1703 & 21 & 146 & 28 & 3 & 160 & 31 & 29.5 & 161 \\
\hline SG-07-038 & 34.3307 & -117.9700 & 1847 & 21 & 178 & 33 & 3 & 195 & 36 & 28.4 & 161 \\
\hline SG-07-041 & 34.3307 & -117.9700 & 1847 & 21 & 83 & 15 & 12 & 120 & 22 & 28.4 & 161 \\
\hline SG-07-042 & 34.3307 & -117.9700 & 1847 & 21 & 98 & 18 & 12 & 142 & 26 & 28.4 & 161 \\
\hline SG-07-044 & 34.3524 & -117.8792 & 2077 & 23 & 143 & 26 & 0 & 143 & 26 & 27.4 & 165 \\
\hline SG-07-045 & 34.3521 & -117.8791 & 2058 & 38 & 594 & 125 & 8 & 737 & 155 & 27.5 & 527 \\
\hline SG-08-100 & 34.3639 & -117.8379 & 1934 & 31 & 79 & 16 & 25 & 155 & 31 & 33.3 & 308 \\
\hline SG-08-101 & 34.3648 & -117.8383 & 1880 & 31 & 338 & 90 & 8 & 419 & 112 & 33.6 & 308 \\
\hline SG-08-102 & 34.3648 & -117.8383 & 1880 & 31 & 329 & 69 & 10 & 430 & 90 & 33.6 & 308 \\
\hline SG-08-105 & 34.3712 & -117.8581 & 2494 & 35 & 96 & 23 & 0 & 170 & 41 & 33.4 & 209 \\
\hline SG-08-106 & 34.3714 & -117.8578 & 2491 & 35 & 118 & 25 & 0 & 210 & 45 & 33.4 & 209 \\
\hline SG-08-108 & 34.3720 & -117.8571 & 2442 & 35 & 166 & 34 & 20 & 285 & 58 & 33.2 & 209 \\
\hline SG-08-110 & 34.3723 & -117.8631 & 2398 & 32 & 163 & 31 & 5 & 187 & 35 & 32.6 & 206 \\
\hline
\end{tabular}

